\title{
High glucose induces ventricular instability and increases vasomotor tone in rats
}

\author{
M. D'Amico ${ }^{* 2}$, R.Marfella ${ }^{* 1}$, F. Nappo ${ }^{1}$, C.Di Filippo ${ }^{2}$, L.De Angelis ${ }^{1}$, L. Berrino ${ }^{2}$, F. Rossi ${ }^{2}$, D. Giugliano ${ }^{1}$ \\ ${ }^{1}$ Department of Geriatrics and Metabolic Diseases, Second University of Naples, Naples, Italy \\ ${ }^{2}$ Department of Experimental Medicine, Section of Pharmacology, Second University of Naples, Naples, Italy
}

\begin{abstract}
Aims/hypothesis. To investigate cardiac repolarization time in streptozotocin-induced diabetic rats and isolated hearts perfused with high glucose concentration.

Methods. We studied the effects of streptozotocin-induced diabetes on the cardiac repolarisation time (Q-T interval) in Sprague-Dawley rats during a 4day period of hyperglycaemia and a subsequent 4day period of normoglycaemia. The Q-T interval was also evaluated in isolated hearts of non-diabetic rats, in condition of high glucose concentration.

Results. Hyperglycaemia in streptozotocin rats increased mean blood pressure and led to a significant $(p<0.001)$ prolongation of $\mathrm{Q}-\mathrm{T}$ values, which normalized after 4 days of normoglycaemia with intravenous insulin infusion. Perfusion of isolated hearts in condition of high glucose concentration caused a significant prolongation of $\mathrm{Q}-\mathrm{T}$ values and increased coronary perfusion pressure $(p<0.001)$. The effects of high glucose were completely prevented by glutathione and almost completely by L-arginine, the
\end{abstract}

natural precursor of nitric oxide. In a condition of normal glucose, L-NAME, an inhibitor of endogenous nitric oxide synthesis, increased both Q-T and CPP values to levels similar to those induced by high glucose $(p<0.001)$. Verapamil completely prevented Q-T lengthening and reduced by about two-thirds CPP values $(p<0.001)$.

Conclusion/Interpretation. Streptozotocin-diabetes in rats produces significant haemodynamic and electric perturbations that are reversed by normoglycaemia. Moreover, high glucose increases Q-T and CPP values in the isolated hearts of non-diabetic rats. The latter effects are reversed by glutathione and L-arginine, partially reversed by verapamil and mimicked by L-NAME. By increasing the production of free radicals, high glucose could reduce nitric oxide availability to target cells inducing a state of increased vasomotor tone and ventricular instability. [Diabetologia (2001) 44: 464-470]

Keywords High glucose, diabetes, streptozotocin, cardiac repolarization, isolated heart.
Received: 12 September 2000 and in revised form: 2 November 2000

Corresponding author: D. Giugliano, Via Emilia 1, 80021 Afragola (NA), Italy

Abbreviations: Q-T interval, cardiac repolarization time; MAP, mean arterial pressure; CPP, coronary perfusion pressure; L-NAME, N-4-Nitro-L-arginine methyl ester; STZ, streptozotocin; NO, nitric oxide.

\footnotetext{
* M. D'Amico and R. Marfella share first autorship.
}

Cardiovascular complications of diabetes commonly lead to considerable morbidity and mortality [1]. Recent prospective studies indicate that glycaemic control of diabetes is an important predictor not only of microvascular disease [2] but also of macrovascular complications, including coronary heart disease [3]. Among the many potential mechanisms proposed to explain why poor glycaemic control of diabetes might predict coronary events and worsen the prognosis both in diabetic and non-diabetic patients after myocardial infarction [4], we recently reported [5-6] that acute hyperglycaemia in normal volunteers can re- 
duce nitric oxide (NO) availability, thus causing a state of increased vasomotor tone and platelet activity and altering the adhesive properties of the endothelium. Impairment of endothelium-dependent relaxation is a common feature in both the conduit and resistance arteries of experimental diabetes in animals, including rats, mice, rabbits, hamsters and dogs [7].

In theory, reduced in vivo NO availability could be responsible for increasing the cytosolic calcium content by impairing $\mathrm{Na}^{+} / \mathrm{K}^{+}$-ATPase activity [8]. This could lead to increased ventricular stiffness, prolonged ventricular relaxation, increased telediastolic ventricular pressure and cardiac repolarization time [9]. A prolonged heart rate-adjusted Q-T (corrected Q-T interval: Q-Tc) is a risk factor for sudden death in patients with the long-Q-T syndrome [10], myocardial infarction patients [11], subjects referred for Holter monitoring [12] and healthy men and women [13]. A recent epidemiologic study in patients with Type II (non-insulin-dependent) diabetes mellitus shows that the prevalence of Q-Tc prolongation is as high as $26 \%$ and is associated with heart disease [14]. Moreover, acute hyperglycaemia could prolong Q-Tc and Q-Tc-dispersion in healthy subjects [15]. The mechanisms by which the hyperglycaemia of diabetes produces ventricular instability, as manifested in Q-Tc prolongation, are, however, not clearly defined.

The first objective of this study was to investigate cardiac repolarization time in streptozotocin-induced diabetic rats. Moreover, the hypothesis that Q-T variations are a primary consequence of hyperglycaemia was tested in isolated working rat hearts perfused with high glucose. Because high glucose could increase oxygen free radical production [16], reduce NO availability [6] and interfere with calcium uptake [17], we investigated if exogenous glutathione, L-arginine, N-4-Nitro-L-arginine methyl ester (L-NAME) and verapamil could counteract the cardiac modifications caused by high glucose.

\section{Subjects and methods}

Streptozotocin-treated rats (STZ rats). Experiments were conducted in 20 male Sprague-Dawley rats (four to six months old and weighing on average $250 \mathrm{~g}$ ). Under sodium pentobarbital anaesthesia $(50 \mathrm{mg} / \mathrm{kg}$ ip) and aseptic conditions, two catheters were inserted into the femoral vein and artery. These were passed subcutaneously and exteriorized on the back of the neck. Incisions were infiltrated with penicillin $\mathrm{G}$ procaine (300000 I. U/ml) and bupivacaine (11.25\%) at closure. The venous catheter was connected to a syringe pump (Harvard Apparatus, Edenbridge, Kent, UK) that ran continuously throughout the study. All solutions contained antibiotic (25000 I. U. penicillin G/rat per day and $0.03 \mathrm{~g}$ mezlocillin/rat per day) and were infused through a Millipore filter (0.22$\mathrm{mm}$, Cathivex, Millipore, Bedford, Mass., USA). The arterial catheter was filled with heparin solution (sodium heparin, 250 I.U.) and connected to a pressure transducer to monitor mean arterial blood pressure (MAP) through a polygraph (Hellige, Freiburg, Germany). On establishing a stable MAP (20-30 min following cannulation), experiments were performed as described below. Four stainless steel wires were implanted at legs to record electrocardiograms (ECG).

After a 20-min stabilization period following the surgical procedure, the basal of MAP, blood glucose and ECG parameters were determined. After this, the rats were disconnected from instrumentation and ECG, and allocated to recover in a cage. Streptozotocin (STZ, $70 \mathrm{mg} / \mathrm{kg}$ i.v) was administered to 14 of the 20 rats. At 4:00 pm, 15 h later, the venous catheter was connected to a syringe pump (Harvard Apparatus, Edenbridge, Kent, UK) and a continuous intravenous infusion of regular insulin $(1.5 \pm 0.5 \mathrm{I} . \mathrm{U} /$ day $)$ was begun and adjusted to yield blood glucose concentrations of about $22 \mathrm{mmol} / \mathrm{l}$ $(396 \mathrm{mg} / \mathrm{l})$ for 4 days. After this period, the insulin dose was increased (4 I.U/day) in order to obtain and maintain normoglycaemia. The other six rats (control group) were monitored for cardiovascular parameters, with the same surgical procedures and without STZ.

Plasma glucose concentration was measured daily with the use of about $50 \mu \mathrm{l}$ of blood from the venous catheter and an Accutrend II glucose analyser.

The ECG (speed $100 \mathrm{~mm} / \mathrm{sec}$ ) and blood pressure were recorded in basal condition, four and eight days after streptozotocin, for $10 \mathrm{~min}$ every $60 \mathrm{~min}$ in $3 \mathrm{~h}$. The time profiles of elecrocardiogram (ECG) parameters were examined from lead II.

Isolated hearts. A total of 67 male Sprague-Dawley rats (four to six months old and weighing on average $250 \mathrm{~g}$ ) were anaesthetised with urethane $(1.2 \mathrm{mg} / \mathrm{kg} /$ i.p. $)$ and then heparanized (sodium heparin, 250 I. U., i.p., $10 \mathrm{~min}$ before heart excision). The hearts were rapidly excised and placed in ice-cold perfusion solution (see constituents below) before coronary perfusion. Hearts were cannulated through the aorta and perfused retrogradely under constant flow $\left(10 \mathrm{ml} \mathrm{min}^{-1}\right)$ using a calibrated roller pump (Gilson, Miniplus-2) with a buffer solution of the following composition: $\mathrm{D}(+)$ glucose, $(\mathrm{mmol} / \mathrm{l}) 11.1$; $\mathrm{CaCl}_{2}, 1.4 ; \mathrm{NaCl}, 118.5 ; \mathrm{NaHCO}_{3}, 25.0 ; \mathrm{MgSO}_{4}, 1.2 ; \mathrm{NaH}_{2} \mathrm{PO}_{4}$, 1.2 and $\mathrm{KCl}, 4.0$. The buffer solution was gassed with $95 \% \mathrm{O}_{2}$ and $5 \% \mathrm{CO}_{2}(\mathrm{pH} 7.4)$ and perfused at $37^{\circ} \mathrm{C}$. Each experiment lasted $2 \mathrm{~h}$.

A total of 67 hearts were used. Eleven were excluded because of unstable preparations. A stable preparation was defined as having a sinus rate of less than 220 beats a minute or a coronary perfusion pressure (CPP) higher than $60 \mathrm{mmHg}$ between 5 and 15 min after the beginning of the perfusion. Any heart not in sinus rhythm during the study was also excluded. The remaining 56 hearts, which satisfied the criteria for a stable preparation, were used. Altogether, 8 hearts were perfused with the buffer solution, as described above, containing D-glucose at a concentration of $11.1 \mathrm{mmol} / \mathrm{l}$, and served as control hearts and 10 hearts were perfused with the buffer solution containing D-glucose at the concentration of $33.3 \mathrm{mmol} / \mathrm{l}$ (high glucose). Another 8 hearts were perfused with D-glucose (33.3 $\mathrm{mmol} / \mathrm{l})$ plus glutathione $(0.3 \mathrm{mmol} / \mathrm{l})$. The buffer solution used to perfuse the other 24 hearts ( 8 for each group) was added with D-glucose $(33.3 \mathrm{mmol} / \mathrm{l})$ plus L-arginine $(10 \mathrm{mmol} / \mathrm{l})$, D-glucose $(11.1 \mathrm{mmol} / \mathrm{l})$ plus L-NAME $(50 \mu \mathrm{mol} / \mathrm{l})$, and D-glucose $(33.3 \mathrm{mmol} / \mathrm{l})$ plus verapamil $(1 \mu \mathrm{mol} / \mathrm{l})$. In order to evaluate the effect of the osmotic solution by itself, the remaining 6 hearts were perfused with a buffer solution containing D-glucose (11.1 mmol/l) plus mannitol $(22.2 \mathrm{mmol} / \mathrm{l})$.

For each heart, a unipolar electrocardiogram (ECG) was recorded by implanting a stainless steel wire electrode into the apex of the left ventricular muscle mass, with a second 


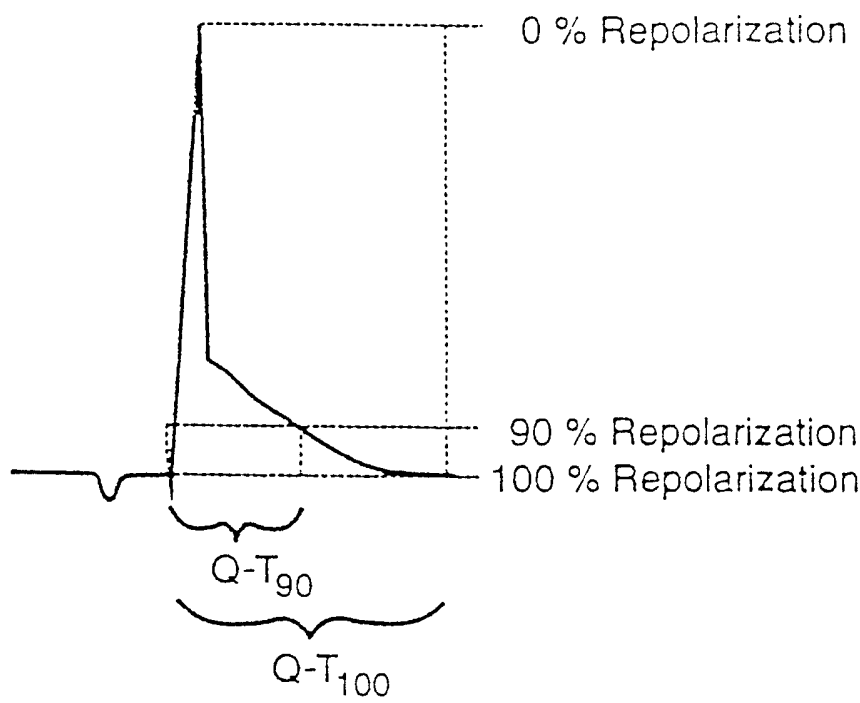

Fig. 1. Measurement of the width of the ventricular complex at $100 \%$ repolarization $\left(\mathrm{Q}-\mathrm{T}_{100}\right)$ in a typical electrocardiogram

electrode connected to the aorta. This electrode arrangement gave clear $\mathrm{P}$ waves and ventricular complexes. A three minutes ECG (speed $50 \mathrm{~mm} / \mathrm{sec}$ ) was carried out every 10 min for $2 \mathrm{~h}$. The CPP was monitored continuously during each study.

An ECG analysis was carried out by a cardiologist who was unaware of the sequence of experiments. The following parameters were calculated: (1) heart rate (R-R interval); (2) the duration between onset of the $P$ wave and onset of the ventricular complex (P-R interval); and (3) the width of the ventricular complex. No separate $\mathrm{T}$ wave is seen in rat ECG, so a conventional measurement of Q-T interval is impracticable. This is because repolarization begins in the apex of the ventricles before depolarization is complete in other parts of the ventricles, secondary to the brief duration of the ventricular action potential. The measure of the width of the ventricular complex was made at $100 \%$ repolarization and is defined as Q-T $\mathrm{T}_{100}$. Figure 1 shows a representative Q-T complex and indicates how Q- $\mathrm{T}_{100}$ is measured. The Q-T value of each experiment was calculated as the mean of the ECG readings done every 10 min.

The CPP in the aortic line was monitored by a Statham Spectramed pressure transducer connected to a chart recorder (Grass, 79E, Quincy, Mass., USA). Air temperature was maintained by means of a heated $\left(37^{\circ} \mathrm{C}\right)$ water jacket. On establishing a stable CPP (20-30 min following cannulation), experiments were done as described previously. The CPP values used for statistical comparisons were calculated either as the mean of each 10 min value throughout the entire experiment or as the mean of the steady-state increment above baseline, if an increase of CPP was evident during an experiment.

Statistical analysis. Data are given as means \pm SE. The MAP and ECG values used for statistical comparisons were expressed either as the mean of each 3 min value throughout the entire experiment or as the mean of the steady-state increment above baseline, if MAP or modifications of ECG parameters increased during an experiment. The statistical analysis was performed with one-way ANOVA, followed by Duncan's multiple range test. A $p$ value of less than $5 \%$ was considered to be statistically significant.
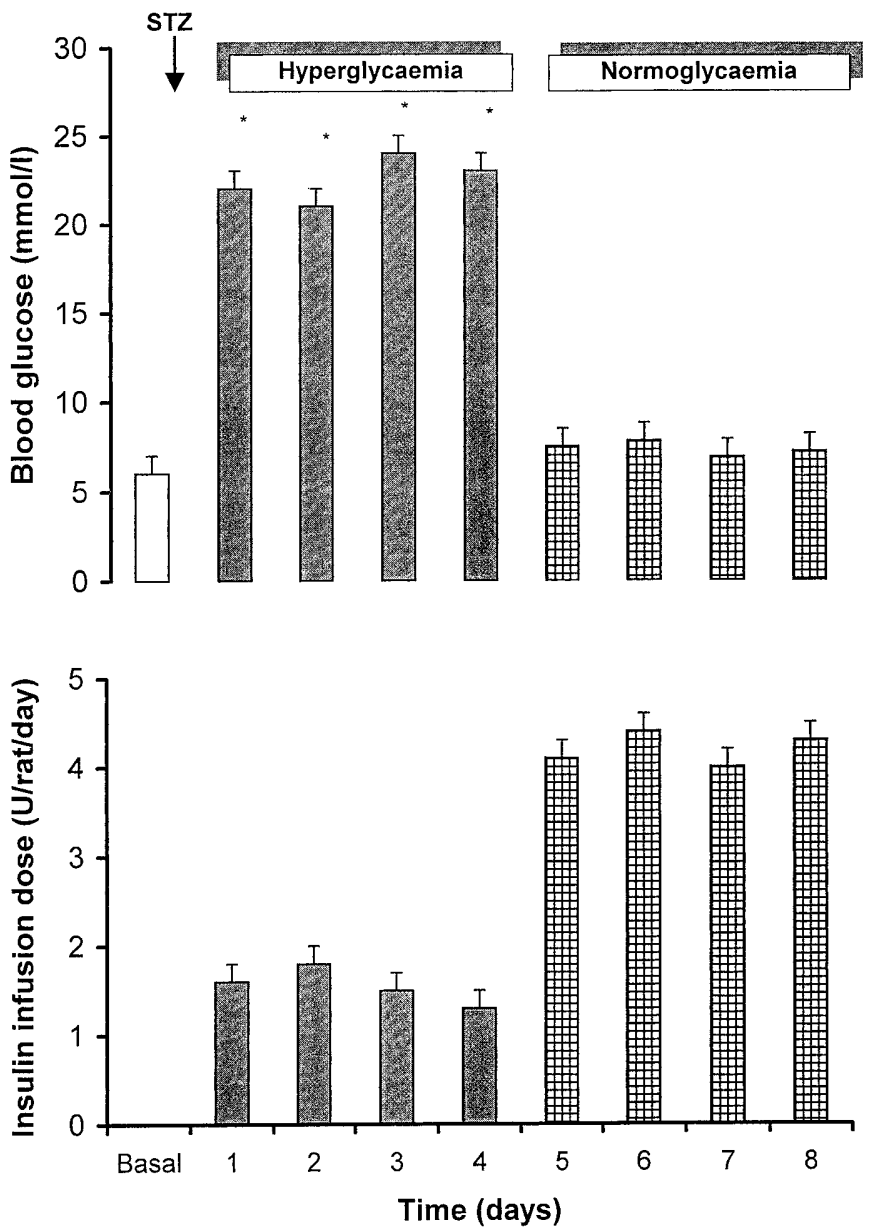

Fig. 2. Blood glucose levels and insulin infusion dose, during the 8-day study in STZ rats. The asterisk indicates significant differences $(p<0.01$ or less) vs basal values

\section{Results}

$S T Z$ rats. Daily blood glucose values are presented in Fig. 2. Blood glucose averaged $6.4 \pm 0.2 \mathrm{mmol} / \mathrm{l}$ in basal conditions and rose to $23.1 \pm 1.9 \mathrm{mmol} / \mathrm{l} 15 \mathrm{~h}$ after STZ administration. The 4-day period of hyperglycaemia resulted in a significant increase in MAP (from $107 \pm 2$ to $116 \pm 3 \mathrm{mmHg}, p<0.05$ ), a reduction of R-R interval (from $169 \pm 10$ to $121 \pm 12 \mathrm{~ms}$, $p<0.05)$ and a significant prolongation of $\mathrm{Q}-\mathrm{T}$ values (from $109 \pm 7 \mathrm{~ms}$ to $165 \pm 12$; $p<0.001$ ) (Fig. 3). Serum sodium and potassium concentrations did not significantly change after STZ-treatment (baseline: $\mathrm{Na}^{+} 138 \pm 3 \mathrm{mmol} / \mathrm{l}, \mathrm{K}^{+} 4.5 \pm 0.8 \mathrm{mmol} / \mathrm{l} ; \mathrm{STZ}: \mathrm{Na}^{+}$ $\left.136 \pm 5 \mathrm{mmol} / 1, \mathrm{~K}^{+} 4.2 \pm 0.5 \mathrm{mmol} / \mathrm{l}: n=4, p=\mathrm{NS}\right)$. Intensive insulin therapy $(4.2 \pm 0.2 \mathrm{U} /$ day $)$ resulted in normalization of blood glucose $(7.4 \pm 1.9 \mathrm{mmol} / \mathrm{l})$ (Fig. 2) which was marked by a decrease of MAP $(108 \pm 4 \mathrm{mmHg})$ and $\mathrm{Q}-\mathrm{T}$ values $(112 \pm 11 \mathrm{~ms})$. The $\mathrm{R}-\mathrm{R}$ intervals also returned to normal values (177 $\pm 11 \mathrm{~ms})$ (Fig. 3). No significant changes in atrioventricular conduction time occurred during the period of hyperglycaemia (PR $54 \pm 8 \mathrm{~ms}$ ) and normogly- 

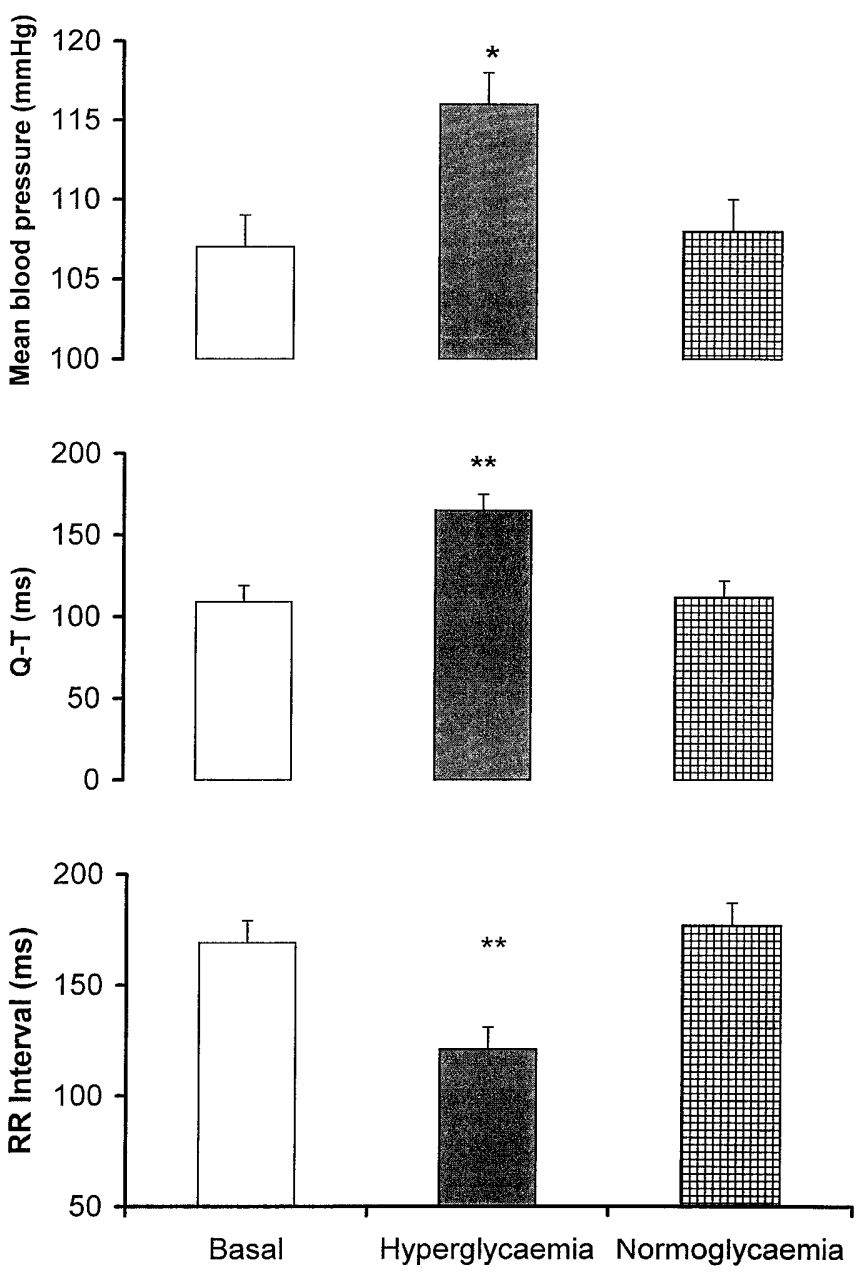

Fig.3. Mean blood pressure, R-R and Q-T intervals, during the 8-day study in STZ rats. ${ }^{*} p<0.05, * * p<0.01$

caemia (PR $59 \pm 7 \mathrm{~ms}$ ), when compared with basal values (PR $61 \pm 7 \mathrm{~ms}$ ). No significant changes of the parameters evaluated were observed in the control group of rats (data not shown).

Isolated hearts. Heart rate (R-R interval, $232 \pm 23 \mathrm{~ms})$ and atrioventricular conduction time $(56 \pm 10 \mathrm{~ms})$ were similar for all groups. Verapamil caused a significant reduction of heart rate $(p<0.05)$ and a prolongation of atrioventricular conduction time $(p<0.05)$ (Table 1$)$.
In the hearts perfused with the control buffer solution, Q-T was $106 \pm 5 \mathrm{~ms}$ and remained steady during all the perfusion time. D-glucose $(33.3 \mathrm{mmol} / \mathrm{l})$ caused a significant prolongation of Q-T $(195 \pm 15 \mathrm{~ms}$, $p<0.001$ vs control study). The effect of high glucose was completely prevented by glutathione: Q-T values $(110 \pm 11 \mathrm{~ms})$ were not significantly different from those observed in the control study. A small, but still significant $\mathrm{Q}-\mathrm{T}$ prolongation, when compared with control study $(117 \pm 10 \mathrm{~ms}, p<0.05)$, was also evident during the L-arginine study, although this prolongation was far less $(p<0.001)$ than the one caused by high glucose. In conditions of normal glucose, L-NAME caused a Q-T prolongation $(182 \pm 15 \mathrm{~ms}, p<0.001$ vs control study) similar to the one caused by high glucose. Verapamil caused an almost complete normalization of the Q-T lengthening induced by high glucose $(113 \pm 7 \mathrm{~ms})$. The Q-T values observed during the mannitol study (108 $\pm 7 \mathrm{~ms})$ did not differ from those obtained in control study (Fig. 4).

In hearts perfused with the control buffer solution, $\mathrm{CPP}$ was $66 \pm 4 \mathrm{mmHg}$. This value was steady during the whole perfusion time. D-glucose $(33.3 \mathrm{mmol} / \mathrm{l})$ caused a significant increase of CPP evident $60 \mathrm{~min}$ after the start of perfusion began and persisting until $120 \mathrm{~min}(119 \pm 19 \mathrm{mmHg}, p<0.001$ vs control study). The effect of high glucose was completely prevented by glutathione: CPP values $(63 \pm 7 \mathrm{mmHg})$ were not significantly different from those observed during the control study. Furthermore L-arginine also normalized the increase of CPP induced by high glucose $(66 \pm 5 \mathrm{mmHg})$. In conditions of normal glucose, LNAME caused a CPP increase $(118 \pm 9 \mathrm{mmHg}$, $p<0.001$ vs control study) similar to the one caused by high glucose. Verapamil reduced by about twothirds the increase of CPP $(86 \pm 6 \mathrm{mmHg}, p<0.001$ vs both control study and high glucose study) induced by high glucose. In the mannitol study, CPP values did not differ from those observed in control study $(68 \pm 5 \mathrm{mmHg})$ (Fig. 4).

\section{Discussion}

In the present study, 4 days of hyperglycaemia in STZ-treated rats caused a significant increase in

Table 1. R-R and P-R intervals during the experimental protocols in isolated hearts

\begin{tabular}{lll}
\hline Experimental protocols & R-R interval (ms) & P-R interval (ms) \\
\hline Control study (D-glucose $11.1 \mathrm{mmol} / \mathrm{l})$ & $232 \pm 23$ & $56 \pm 10$ \\
High glucose (D-Glucose $33.3 \mathrm{~m}$ ) & $229 \pm 25$ & $54 \pm 12$ \\
Glutathione (D-Glucose $33.3 \mathrm{mmol} / \mathrm{l}$, Glutathione $0.3 \mathrm{mmol} / \mathrm{l})$ & $230 \pm 21$ & $52 \pm 9$ \\
L-Arginine (D-Glucose $33.3 \mathrm{mmol} / \mathrm{l}, \mathrm{L}-$ Arginine $10 \mathrm{mmol} / \mathrm{l})$ & $235 \pm 18 \pm 11$ \\
L-NAME (D-Glucose $11.1 \mathrm{mmol} / \mathrm{l}$, L-NAME $50 \mu \mathrm{mol} / \mathrm{l})$ & $227 \pm 19$ & $57 \pm 4$ \\
Verapamil (D-Glucose $33.3 \mathrm{mmol} / \mathrm{l}$, Verapamil $1 \mu \mathrm{mol} / \mathrm{l})$ & $310 \pm 28^{\mathrm{a}}$ & $81 \pm 16^{\mathrm{a}}$ \\
Mannitol (D-Glucose $11.1 \mathrm{mmol} / \mathrm{l}$, Mannitol $22.2 \mathrm{mmol} / \mathrm{l})$ & $224 \pm 24$ & $55 \pm 12$ \\
\hline
\end{tabular}

${ }^{\mathrm{a}} p<0.01$ vs control study 

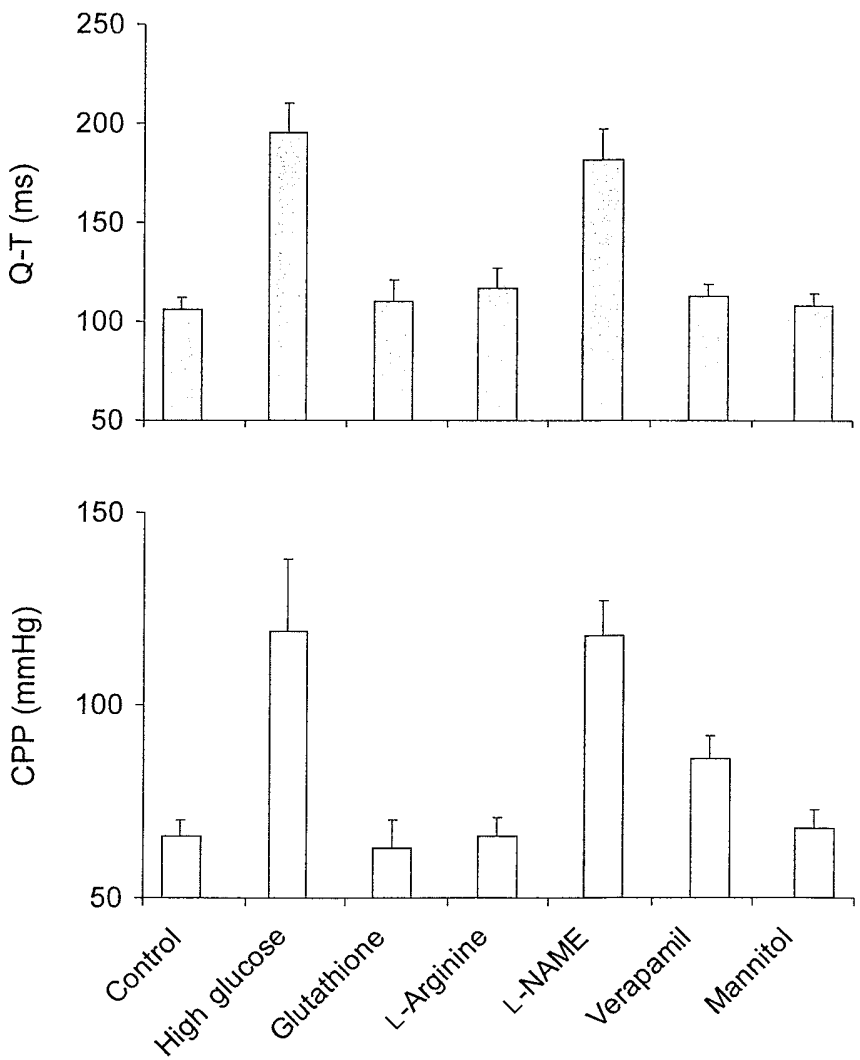

Fig.4. Q-T and CPP variations during the experimental protocols in isolated heart

mean blood pressure and altered the cardiac activity, as shown by the prolongation of the ventricular repolarization time (Q-T interval) and the increase in heart rate. All these effects were normalized on the restoration of normoglycaemia obtained with insulin infusion. An increase of blood pressure and heart rate has been observed in diabetic rats after a short period of poor glycaemic control [18], as well as in normal humans rendered acutely hyperglycaemic [19]. Moreover, streptozotocin-induced diabetes in rats increases action potential duration in isolated myocytes altering $\mathrm{K}^{+}$currents [20]. The mechanisms by which hyperglycaemia could influence blood pressure and cardiac ventricular time are not clear. Hyperglycaemia produces an increase of sympathetic activity [21] and alters the renin-angiotensin system [22]. Moreover, it could be responsible for Q-Tc prolongation and vasoconstriction by increasing the cytosolic calcium content through the reduction of $\mathrm{Na}^{+} / \mathrm{K}^{+}$-ATPase activity by depressed NO formation [8].

An increase of circulating FFA levels, as a consequence of STZ-induced hypoinsulinaemia, might also have contributed to alterations of the Q-T interval; FFA could induce endothelial dysfunction [23] and prolong Q-T interval in healthy subjects [24]. It has been previously observed, however, that Q-Tc increases in healthy subjects in both hyperglycaemic- hyperinsulinaemic and hyperglycaemic-normoinsulinemic conditions [25]. This has led to the hypothesis that insulin deficiency, at least in humans and in vivo, is not essential for cardiac repolarization. On the other hand, a perturbation of serum electrolytes can also be excluded, since plasma sodium and potassium concentrations did not change 4 days after STZ-induced diabetes in the rats. Moreover, stimulation of electrolyte transport systems in the kidney, occurring in short-term treatment with STZ, could prevent excessive modifications of serum electrolytes [26].

The data observed in isolated rat hearts suggest that Q-T prolongation is a primary consequence of hyperglycaemia. Indeed, high glucose concentrations in the perfusion medium of isolated working rat hearts produced a significant prolongation of the Q$T$ interval and a parallel increase of CPP. The effects of high glucose on Q-T and CPP values were completely prevented by glutathione, a free radical scavenger, and almost completely by L-arginine, the natural precursor of NO. Taken together, these observations suggest that high glucose increases the production of free radicals, which could suppress NO, reducing its availability for target cells. By increasing NOavailability, L-arginine might have counterbalanced the reduced availability of NO induced by high glucose. On the other hand, depressed NO formation is often associated with increased free radicals production [7]. Further support for this hypothesis comes from the results of the L-NAME study. This compound, which is a competitive inhibitor of NO-sinthase, mimicked the effects induced by high glucose on both Q-T and CPP. This hypothesis is compatible with the contribution of NO to the protective role of the heart in pathological conditions [27].

While the increased vasomotor tone associated with reduced NO availability could explain, at least in part, the increases in CPP observed during high glucose, the mechanisms by which high glucose can produce the disturbed myocardial membrane function, which is believed to lead to electrical instability, are not clear. A reduction of $\mathrm{Na}^{+} / \mathrm{K}^{+}$-ATPase activity through depressed $\mathrm{NO}$ formation [8], the inhibition of $\mathrm{Ca}^{2+}$-ATPase activity [28], a depressed $\mathrm{Na}^{+} / \mathrm{Ca}^{2+}$ exchanger activity [29] and the activation of $\mathrm{Na}^{+} / \mathrm{H}^{+}$ antiport [30] could be implicated. In this chain of events, reduced NO-availability might contribute to the rapid perturbations of intracellular ionic homeostasis leading to changes in intracellular $\mathrm{Ca}^{2+}$ concentration [31]. Indeed, 4-6 days of STZ-induced diabetes prolonged considerably both contraction and relaxation in isolated ventricular myocytes, suggesting a rapid alteration in the processes regulating myocyte shortening and re-lengthening, which probably include impaired $\mathrm{Ca}^{2+}$ sequestration or extrusion [32].

In red blood cells taken from healthy individuals and assayed for cation transmembrane traffic by nu- 
clear magnetic resonance spectroscopy, incubation with high glucose $(15 \mathrm{mmol} / \mathrm{l})$ increases intracellular $\mathrm{Ca}^{2+}$ while decreasing $\mathrm{Mg}^{2+}$; the same alteration of intracellular ionic content occurs during oral glucose testing in healthy subjects [33]. Moreover, increased intracellular calcium is common in diabetic patients [17]. High glucose concentrations could depress NO formation by increasing free radical production $[16$, 34]. This in turn, through the inhibition of $\mathrm{Ca}^{2+}-\mathrm{AT}$ Pase and $\mathrm{K}^{+} / \mathrm{Na}^{+}$-ATPase activity, would increase cytosolic free calcium, leading to a prolongation of myocardial repolarization time and increased coronary constriction. On the other hand, reduced NO-availability, oxidative stress and impaired intracellular calcium are common denominators of vascular dysfunction and risk factors for cardiovascular diseases, including Q-T prolongation [35]. This could have influenced the Q-T interval and coronary pressure in our model of the working heart. Supporting this hypothesis, the calcium channel blocker verapamil normalized Q-T intervals and partially reduced CPP values increased by high glucose.

The length of the Q-T interval, which is easily obtained from the standard resting electrocardiogram, represents the time interval between the start of activation of the ventricle and completion of its repolarization. The Q-T interval is influenced by the autonomic tone [36] and represents an index of myocardial refractoriness and electrical stability; these are critical determinants of ventricular fibrillation and sudden death [37]. An association between a prolonged Q-T interval and sudden cardiac death has been found in various diseases including coronary artery disease and heart failure [38, 39]. In diabetic patients, Q-T interval lengthening has been linked to an increased risk for unexpected death and total mortality [40, 41]. A recent study shows that acute hyperglycaemia in normal subjects produces a significant increase of Q-Tc and Q-Tc dispersion [15]. A study [4] has reported that stress hyperglycaemia with myocardial infarction is associated with an increased risk of in-hospital mortality in patients with and without diabetes. Unfortunately, Q-T values were not reported in this study.

In conclusion, we show that high glucose concentrations cause significant haemodynamic and electrical changes in experimental diabetes and in isolated working rat hearts. The alterations observed in isolated rat hearts are reversed by glutathione and L-arginine, and partially prevented by verapamil. High glucose might act through reduced NO availability, as is also suggested by the similarity of the effects brought about by L-NAME. These results suggest that high glucose could be deleterious to cardiac functions and offer novel mechanisms through which acute increases of plasma glucose concentrations act as an independent contribution to the development of cardiovascular complications in diabetes mellitus [42, 43].

\section{References}

1. Stamler J, Vaccaro O, Neaton D, Wentworth D (1993) For the Multiple Risk Factor Intervention Trial Research Group. Diabetes, other risk factors and 12-yr cardiovascular mortality for men screened in the Multiple Risk Factor Intervention Trial. Diabetes Care 16: 434-444

2. DCCT Research Group (1993) The effect of intensive treatment of diabetes on the development and progression of long-term complications in insulin-dependent diabetes mellitus. N Engl J Med 329: 977-986

3. Kuusisto J, Mikkanen L, Pyorala K, Laakso M (1994) NID$\mathrm{DM}$ and its metabolic control predict coronary artery disease in elderly people. Diabetes 43: 960-967

4. Capes SE, Hunt D, Malmberg K, Gerstein HC (2000) Stress hyperglycaemia and increased risk of death after myocardial infarction in patients with and without diabetes: a systematic overview. Lancet 355: 773-778

5. Giugliano D, Marfella R, Coppola L et al. (1997) Vascular effects of acute hyperglycemia in humans are reversed by L-Arginine. Evidence for reduced availability of nitric oxide during hyperglycaemia. Circulation 95; 1783-1790

6. Marfella R, Esposito K, Giunta R et al. (2000) Circulating adhesion molecules in humans role of hyperglycemia and hyperinsulinemia. Circulation 101: 2247-2251

7. Pieper GM (1998) Review of alteration in endothelial nitric oxide production in diabetes. Protective role of Arginine on endothelial dysfunction. Hypertension 31: 1047-1060

8. Gupta S, Sussman I, McArtliur CS, Tornheim K, Cohen RA, Ruderman NB (1992) Endothelium-dependent inhibition of $\mathrm{Na}+-\mathrm{K}+$ ATPase activity in rabbit aorta by hyperglycemia. Possible role of endothelium-derived nitric oxide. J Clin Invest 90: 727-732

9. Joffe II, Travers KE, Perreault-Micale CL, Hampton T, Katz SE, Morgan JP, Douglas PS (1999) Abnormal cardiac function in the Streptozocin-induced non-insulin-dependent diabetic rat: non-invasive assessment with Doppler echocardiography and contribution of nitric oxide pathway. J Am Coll Cardiol 34: 2111-2119

10. Jervell A, Lange-Nielsen F (1957) Congenital deaf mutism: functional heart disease with prolongation of the Q-T interval, and sudden death. Am Heart J 54: 59-68

11. Peters RW, Byington RP, Barker A, Yusuf S, BHAT Study Group (1990) Prognostic value of prolonged ventricular repolarization following myocardial infarction: the BHAT experience. J Clin Epidemiol 43: 167-172

12. Algra A, Tijssen JGP, Roelandt JRTC, Pool J, Lubsen J (1991) Q-Tc prolongation measured by standard 12-lead electrocardiography is an independent risk factor for sudden death due to cardiac arrest. Circulation 83: $1888-1894$

13. Schouten EG, Dekker JM, Meppelink P, Kok FJ, Vandeubroucke JP, Pool J (1991) Q-T-interval prolongation predicts cardiovascular mortality in an apparently healthy population. Circulation 84: 1516-1523

14. Borra M, Veglio M, Bruno G et al. (1999) Prevalence of QTc prolongation in Type II diabetic: an Italian populationbased cohort. Diabetologia 42 [Suppl 1]: A295 Abstract

15. Marfella R, Rossi F, Giugliano D (1999) Q-Tc dispersion, hyperglycemia and hyperinsulinemia. Circulation 100: e150

16. Tesfamarian B, Cohen RA (1992) Free radicals mediate endothelial cell dysfunction caused by elevated glucose. Am J Physiol 263: H321-H326

17. Levy J, Gavin JR 3rd, Bowers JR (1994) Diabetes mellitus: a disease of abnormal calcium metabolism ? Am J Med 96: 260-273 
18. Brands MW, Hopkins TE (1996) Poor glycemic control induces hypertension in diabetes mellitus. Hypertension 27: 735-739

19. Marfella R, Nappo F, De Angelis L, Paolisso G, Tagliamonte MR, Giugliano D (2000) Hemodynamic effects of acute hyperglycemia in type 2 diabetic patients. Diabetes Care 23: 658-663

20. Casis O, Gallego M, Iriarte M, Sànchez-Chapula JA (2000) Effects of diabetic cardiomiopathy in regional electrophysiologic characteristics of rat ventricle. Diabetologia 43: 101-109

21. Marfella R, Verrazzo G, Acampora R et al. (1995) Glutathione reverses systemic hemodynamic changes induced by acute hyperglycaemia in health subjects. Am J Physiol: E1167-E1171

22. Miller JA, Floras JS, Zinman B, Skorecki KL, Logan AG (1996) Effect of hyperglycemia on arterial pressure, plasma renin activity and renal function in early diabetes. Clin Sci (Colch) 90: 189-193

23. Steinberg HO, Tarshoby M, Monestel R et al. (1997) Elevated circulating free fatty acid impair endothelium-dependent vasodilation. J Clin Invest 100: 1230-1239

24. Marfella R, De Angelis L, Nappo F et al. (2000) Elevated plasma free fatty acid concentrations prolong cardiac repolarization in healthy subjects. Am J Clin Nutr (in press)

25. Marfella R, Nappo F, De Angelis L, Siniscalchi M, Rossi F, Giugliano D (2000) The effect of acute hyperglycaemia on Q-Tc duration in healthy man. Diabetologia 43: 571-575

26. Tomlison KC, Gardiner SM, Hebden A, Bennett T (1992) Functional consequences of streptozotocin-induced diabetes mellitus, with particular reference to the cardiovascular system. Pharmacol Rev 44: 103-150

27. Ma XL, Gao F, Liu GL (1999) Opposite effects of nitric oxide and nitroxyl on postischemic myocardial injury. Proc Nat Acad Sci USA 96: 14617-14622

28. Davis FB, Davis PJ, Gerard N et al. (1985) The effect of in vivo glucose administration on human erythrocyte $\mathrm{Ca}^{2}+$ ATPase activity and on enzyme responsiveness in vitro to thyroid hormone and calmodulin. Diabetes 34 : 639-646

29. Schaffer SW, Ballard-Croft C, Boerth S, Allo SN (1997) Mechanisms underlying depressed $\mathrm{Na}^{+} / \mathrm{Ca}^{2+}$ exchanger activity in the diabetic heart. Cardiovasc Res 34: 129-136

30. Williams B, Howard KL (1994) Glucose-induced changes in $\mathrm{Na}^{+} / \mathrm{H}^{+}$antiport activity and gene expression in cultured vascular smooth muscle cells. Role of protein kinase C. J Clin Invest 93: 2623-2631

31. Simard JM, Li X (2000) Functional integrity of endothelium determines $\mathrm{Ca}^{2+}$ channel availability in smooth muscle: involvement of nitric oxide. Pflugers Arch 439: 752-758

32. Davidoff A, Ren J (1997) Low dose insulin and high glucose induce abnormal relaxation in cultured adult rat ventricular myocytes. Am J Physiol 272: H159-H167

33. Tepel H, Schlotmann K, Barenbrock H, Kisters K, Klaus T, Spieker C (1995) Lymphocytic $\mathrm{Na}+-\mathrm{H}+$ exchange increases after an oral glucose challenge. Circ Res 77: 1024-1029

34. Giugliano D, Paolisso G, Ceriello A (1996) Oxidative stress and diabetic vascular complications. Diabetes Care 19: 257-267

35. Granger DN (1999) Ischemia-reperfusion: mechanisms of microvascular dysfunction and the influence of risk factors for cardiovascular disease. Microcirculation 6: 167-178

36. Ahnve S, Vallin H (1982) Influence of heart rate and inhibition of autonomic tone on the Q-T interval. Circulation 65: 435-439

37. Vlay SC, Mallis GI, Brown EJ, Cohn PF (1984) Documented sudden cardiac death in prolonged Q-T syndrome. Arch Intern Med 144: 833-834

38. Barr CS, Nans A, Freeman M, Lang C, Struthers AD (1994) Q-T dispersion and sudden unexpected death in chronic heart failure. Lancet 343: 327-329

39. Bellavere F, Ferri M, Guarini G (1988) Prolonged Q-T period in diabetic autonomic neuropathy: a possible role in sudden cardiac death. Br Heart J 59: 379-383

40. Ewing DJ, Boland O, Neilson JMM, Cho CG, Clarke BF (1991) Autonomic neuropathy, Q-T interval lengthening, and unexpected deaths in male diabetic patients. Diabetologia 34: 182-185

41. Jermendy C, Tòth L, Voros P, Koltai MZ, Pogatsa G (1991) Cardiac autonomic neuropathy and Q-T interval length. A follow-up study in diabetic patients. Acta Cardiol 46: 189-200

42. Ceriello A (1998) The emerging role of post-prandial spikes in the pathogenesis of diabetic complications. Diabetic Med 15: 188-193

43. Ceriello A (2000) The post prandial state and cardiovascular disease: relevance to diabetes mellitus. Diabetes Metab Rev 16: $125-132$ 